\title{
Pathogenesis of eosinophilic vs. non-eosinophilic chronic rhinosinusitis with nasal polyposis in Vietnamese
}

\author{
L.M. Ky ${ }^{1,2}$, N.T.T. Uyen ${ }^{3}$, N.D. Phuc ${ }^{3}$, N.T. Xuong ${ }^{4}$, T.X. Hai ${ }^{5}$, \\ L.A. Tuan ${ }^{3}$ and V.T.M. Thuc ${ }^{1}$ \\ ${ }^{1}$ National Otorhinolaryngology Hospital of Vietnam, \\ ${ }^{2}$ Vietnam National University (VNU), Hanoi \\ ${ }^{3}$ Ear, Nose and Throat (ENT) Department Hanoi Medical University-Hanoi- \\ Vietnam \\ ${ }^{4}$ ENT Depart. National Peadiatric Hospital of Vietnam \\ ${ }^{5}$ Nghe An Maternity - Pediatric Hospital, Viet Nam \\ Corresponding author: V.T.M. Thuc \\ E-mail: vuminhthuc2010@yahoo.com.vn
}

Genet. Mol. Res. 20 (1): gmr18733

Received December 30, 2019

Accepted April 20, 2020

Final Revision January 25, 2021

Published March 25, 2021

DOI http://dx.doi.org/10.4238/gmr18733

\begin{abstract}
The study of the characteristics of non-eosinophilic and eosinophilic chronic polyposis rhinosinusitis $(C R S w N P)$ is necessary to improve understanding of the pathophysiological mechanisms of this disease and determine the optimal treatment strategy. We studied the specific features of eosinophilic and noneosinophilic $C R S w N P$ in Vietnamese patients. Patients (48 male and 35 female) with a diagnosis of $C R S w N P$ took part in the work. Patients were operated on at the National ENT Hospital from 9/2017 to $8 / 2018$. Based on a study of the pathology of nasal polyps, $C R S w N P s$ were classified as eosinophilic or non-eosinophilic. In men, $35 \%$ had eosinophilic $C R S w N P$ and $65 \%$ had non- eosinophilic $C R S w N P$. In the subgroup of women, eosinophilic $C R S w N P$ was observed in $31 \%$ and non-eosinophilic $C R S w N P$ in $69 \%$. In total, $34 \%$ of 83 people had eosinophilic $C R S w N P$. The average duration of eosinophilic $C R S w N P$ disease was $45.0 \pm 43.1$ months; noneosinophilic $C R S w N P$ was $25.5 \pm 20.5$ months. In this cohort of patients, $8.4 \%$ suffered from bronchial asthma, and a high probability
\end{abstract}


of this pathology was found in combination with the eosinophilic CRSwNP (OR $=5.76 ; 1.04-31.89$ CI 95\%; $\mathrm{P}=0.045)$. The proportion of allergic rhinitis with eosinophilic $C R S w N P$ was $39.3 \%$, and with non-eosinophilic $C R S w N P$ was $12.7 \%$. The share of uni-and bilateral eosinophilic CRSwNPs was 10.7 and $89.3 \%$, while noneosinophilic $C R S w N P s$ were 41.8 and $58.2 \%$, respectively. Thus, $C R S w N P$ is a complex heterogeneous inflammatory disease. Eosinophilia plays an important role in the pathogenesis of this disease and significantly worsens the clinical picture. There are significant differences in the duration of the pathological manifestations, the presence of allergic rhinitis, bronchial asthma and the severity of polyps in patients with eosinophilic and noneosinophilic $C R S w N P$.

Key words: Chronic rhinosinusitis; Nasal polyposis; Bronchial asthma; Allergic rhinitis

\section{INTRODUCTION}

Chronic rhinosinusitis (CRS) is a common inflammatory pathology of the nasal mucosa, in particular; according to epidemiological studies, this chronic disease of the cavity of the sinonasal canal affects $5-28 \%$ of the population depending on the region and ethnicity (Shi et al., 2019). CRS is classified according to the absence (CRSsNP) or the presence of nasal polyps (Chronic rhinosinusitis with nasal polyp - CRSwNP) and is a heterogeneous disease in the pathogenesis of which various immune cells and inflammatory mediators are involved (Bachert and Akdis, 2016). It has been established that the patterns of inflammation of CRS are eosinophilic or neutrophilic, in particular, CRSwNP is characterized by eosinophilic inflammation with elevated levels of Th2 cytokines (Tomassen et al., 2016). However, recent studies have shown that CRS can be defined as a continuum of inflammatory processes with variable and non-mutually exclusive immunological markers (Workman, et al., 2018).

A sign of $C R S w N P$ is the loss of healthy barrier function in sinonasal epithelial cells, increased permeability and decreased epithelial resistance (Watelet et al., 2015). The presence of tissue eosinophilia in $C R S w N P$ is often associated with extensive sinus damage, a higher number of postoperative complications, a deterioration in the overall quality of life, and an increased rate of polyp relapse (Lou et al., 2018). One of the common comorbid diseases in CRSwNP is bronchial asthma (Philpott et. al., 2018). Its prevalence in this category of patients can reach $30-70 \%$ depending on ethnicity, smoking status, age, and severity of the disease (Fokkens et al., 2019).

Treatment of $C R S w N P$ depends on the severity of the pathological process. Intranasal glucocorticoids and saline irrigation are recommended for patients with mild symptoms, with more pronounced symptoms, short-term courses of systemic glucocorticoids can be used, and if they are ineffective, the operation to remove polyps is justified (Hopkins, 2019). At the same time, the establishment of inflammatory patterns and the study of other characteristics of eosinophilic and non-eosinophilic CRSwNPs will not only improve understanding of pathophysiological mechanisms but also help in choosing 
the optimal treatment strategy. In this regard, the aim of the study was to study the specific features of eosinophilic and non-eosinophilic $C R S w N P$ in Vietnamese.

\section{MATERIAL AND METHODS}

In this work, 83 patients (48 male and 35 female) with a diagnosis of $C R S w N P$ were operated on at the National ENT Hospital between 9/2017 and 8/2018. At the first stage, an anamnesis was collected: nationality, gender, age, information about heredity, allergic reactions, the presence of concomitant pathologies, and the duration of CRS. The presence of comorbid diseases: bronchial asthma and allergic rhinitis were determined. Electrocardiography, an X-ray examination of the chest organs, a study of the function of external respiration, a general and biochemical blood test, a general urinalysis, and a coagulogram were also performed. To assess the control of bronchial asthma, all patients were consulted by a pulmonologist, and they also filled out validated questionnaires: Asthma Control test and Asthma Control Questionnare-5. Along with the standard ENT examination, all patients underwent an endoscopic examination of the nasal cavity. The $C R S w N P$ type was histologically determined: eosinophilic (edema, goblet cell hyperplasia, thickening of the basement membrane, and leukocyte infiltration with increased eosinophil migration into the polyp tissue) and non-eosinophilic (Figure 1).

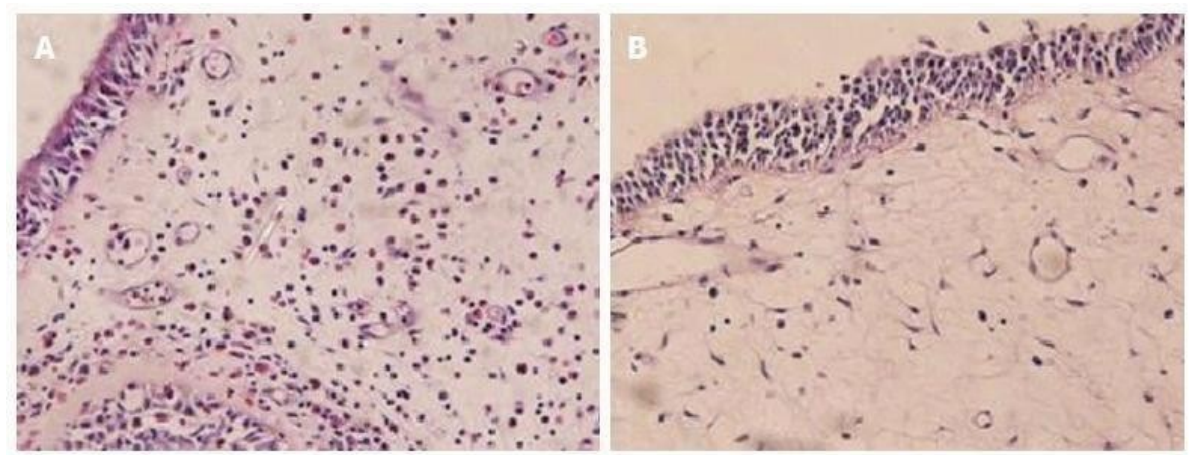

Figure 1. Eosinophil polyp: Polyp specimen 400(10x40) + eosinophil/HPF(high-power field) $\geq 10$ eosinophil polyp + eosinophil/HPF $<10$ non- eosinophil polyp. (A) - Eosinophil Polyp. (B) - Non-eosinophil Polyp.

\section{Study inclusion criteria}

Patients with a diagnosis of $C R S w N P$ were operated on at the National ENT Hospital between 9/2017 and 8/2018 from whom written consent was obtained to participate in the study

\section{Exclusion criteria}

Congenital malformations, in particular of otorhinolaryngological organs, oncological diseases, insufficient patient compliance.

The study design, informed consent form was reviewed and approved by the expert bioethics committee of the National ENT Hospital. Statistical analysis was performed using generally accepted methods using the Statistica 10.0 software package (StatSoft, USA). The 
statistical significance of the differences was determined using the t-criterion for independent samples. For the variables of interest, the odds ratio (OR) and the 95 percent confidence interval (CI) were calculated. Differences were considered statistically significant at $\mathrm{P}<0.05$.

\section{RESULTS}

The average duration of eosinophilic $C R S w N P$ disease was $45.04 \pm 43.1$ months; for non-eosinophilic $C R S w N P$, it was $25.5 \pm 20.5$ months. The distribution of test subjects by gender is presented in Table 1. It can be seen that the assessment of the occurrence of eosinophilic and non-eosinophilic $C R S w N P$ in Vietnamese people taking into account gender did not reveal a steady trend $(\mathrm{OR}=1.196,95 \% \mathrm{CI}=0.474-3.023, \mathrm{P}=0.7)$.

Table 1. Gender distribution of patients with eosinophilic and non-eosinophilic chronic rhinosinusitis with nasal polyposis.

\begin{tabular}{llll}
\hline Gender & Eosinophil $\boldsymbol{C R S} \boldsymbol{w} \boldsymbol{N P}$ & Non-eosinophil $\boldsymbol{C R S \boldsymbol { N } \boldsymbol { P }}$ & Total \\
\hline Male, $\mathrm{n}$ & 17 & 31 & 48 \\
Female, n & 11 & 24 & 35 \\
SUM, n & 28 & 55 & 83 \\
\hline
\end{tabular}

In men, 35.4\% had eosinophilic $C R S w N P$ and $64.6 \%$ had non-eosinophilic $C R S w N P$. In the subgroup of women, eosinophilic CRSwNP was observed in $31.4 \%$ and non-eosinophilic $C R S w N P$ in $68.6 \%$. In total, of 83 people, $33.7 \%$ had eosinophilic CRSwNP. (Table 2).

The next step was to look for associations between $C R S w N P$ and bronchial asthma

Table 2. Asthma associated with eosinophilic and non-eosinophilic chronic rhinosinusitis with nasal polyposis.

\begin{tabular}{lllll}
\hline Asthma & Eosinophil $\boldsymbol{C R S w \boldsymbol { N }}$ & Non-eosinophil $\boldsymbol{C R S w \boldsymbol { P }}$ & Total $(\mathbf{n}, \boldsymbol{\%})$ & P \\
\hline Yes & 5 & 2 & 7 & $<0,05$ \\
No & 23 & 53 & 76 & \\
SUM (n,\%) & 28 & 55 & 83 & \\
\hline
\end{tabular}

In this patient cohort, $8.4 \%$ suffered from bronchial asthma (6.0\% with eosinophilic $C R S w N P, 2.4 \%$ with non-eosinophilic $C R S w N P$ ) (Table 2). The results indicate that the chances of detecting this concomitant disease are significantly higher in the eosinophilic $C R S w N P$ group; i.e., this pathology is directly related to the likelihood of comorbid bronchial asthma.

Allergic rhinitis is a common complication of CRS. In our study, symptoms of allergic rhinitis were significantly more often observed with eosinophilic $C R S w N P(\mathrm{P}<$ 0.001) (Figure 2). 


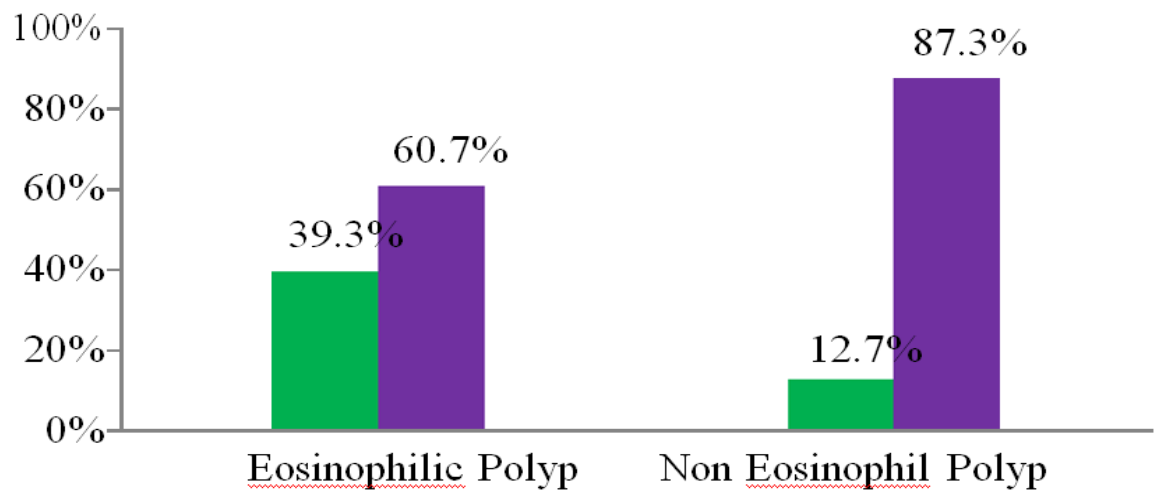

Figure 2. Symptoms of allergic rhinitis in patients with eosinophilic and non-eosinophilic chronic rhinosinusitis with nasal polyposis

An assessment of the localization of nasal polyps showed (Table 3) that the unilateral position was found in $31.3 \%$ of cases, while the bilateral position was found in $68.7 \%$ of cases. The share of unilateral and bilateral eosinophilic CRSwNPs was 10.7 and $89.3 \%$, respectively, while non-eosinophilic $C R S w N P S$ were 41.8 and $58.2 \%$, respectively. These data show that eosinophilic $C R S w N P s$ are predominantly bilaterally localized.

Table 3. Nasal polyp localization in patients with eosinophilic and non-eosinophilic chronic rhinosinusitis with nasal polyposis.

\begin{tabular}{lllllll}
\hline Nasal Polyp & Eosinophil $\boldsymbol{C R S} \boldsymbol{w} \boldsymbol{N P}$ & Non-eosinophil $\boldsymbol{C R S w \boldsymbol { P }}$ & $\mathbf{S u m}(\mathbf{n}, \boldsymbol{\%})$ & $\mathbf{R}$ & $\mathbf{C I}$ & $\mathbf{p}$ \\
\hline unilateral & 3 & 23 & 26 & 0,167 & $0,04-0,62$ & $<0,05$ \\
bilateral & 25 & 32 & 57 & & & \\
\hline
\end{tabular}

The study of the level of nasal polyps is of interest (Table 4). The results of our study demonstrate the presence of a statistically significant pattern in polyp levels. The highest number of eosinophilic CRSwNPs detected as well as non-eosinophilic CRSwNPS was of the 2nd level.

Table 4. Nasal polyp levels in patients with eosinophilic and non-eosinophilic chronic rhinosinusitis.

\begin{tabular}{llll}
\hline Nasal polyp & Eosinophil $\boldsymbol{C R S} \boldsymbol{w} \boldsymbol{N P}$ & Non-eosinophil $\boldsymbol{C R S \boldsymbol { N } \boldsymbol { P }}$ & p \\
\hline Level 1 & 8 & 24 & 0,039 \\
Level 2 & 20 & 46 & \\
Level 3 & 16 & 13 & \\
Level 4 & 9 & 7 & \\
\hline
\end{tabular}

The assessment of X-ray changes in sinusitis according to the Lund-Mackay score is widely used in clinical studies. Inflammatory changes and lesions were more pronounced with Eosinophil CRSwNP (Figure 3). 


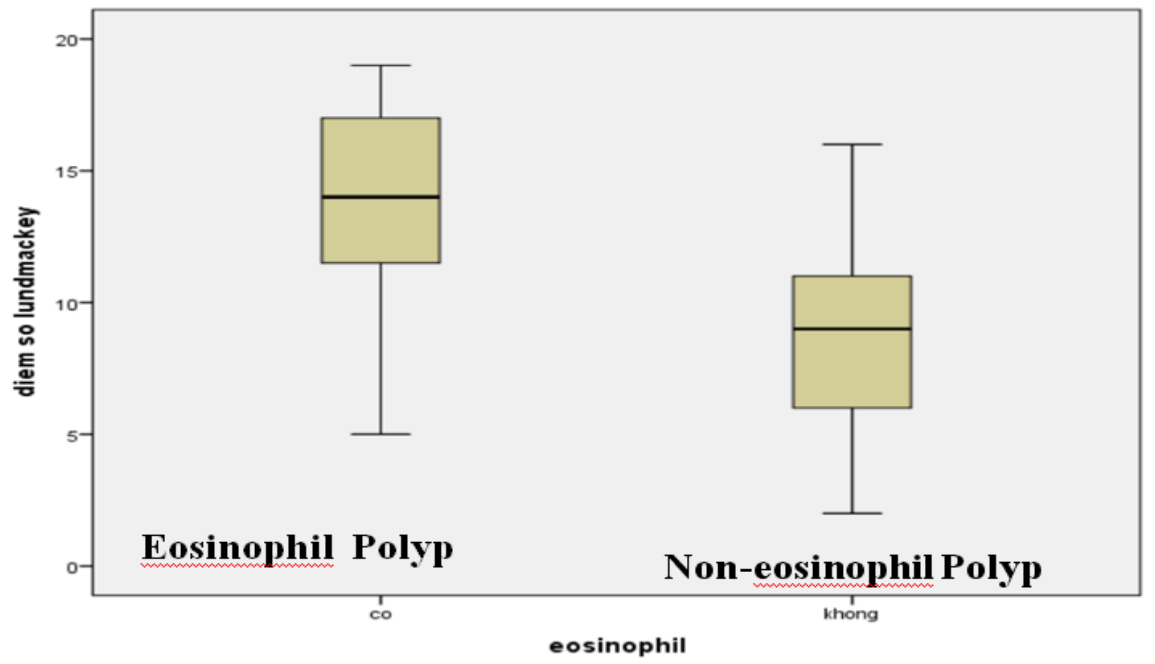

Figure 3. Lund-Mackay Score. Note: Lund-Mackay score of Eosinophil CRSwNP group: 13,46 $\pm 4,0$; LundMackay score of Non-eosinophil. CRSwNP group: $8.54 \pm 4.5(\mathrm{P}=0.004)$

Additionally, we estimated the number of eosinophils in the blood. The results show that with Eosinophil $C R S w N P$ the number of eosinophils in the blood is statistically significantly higher in comparison with the Non-Eosinophil CRSwNP group (Figure 4).

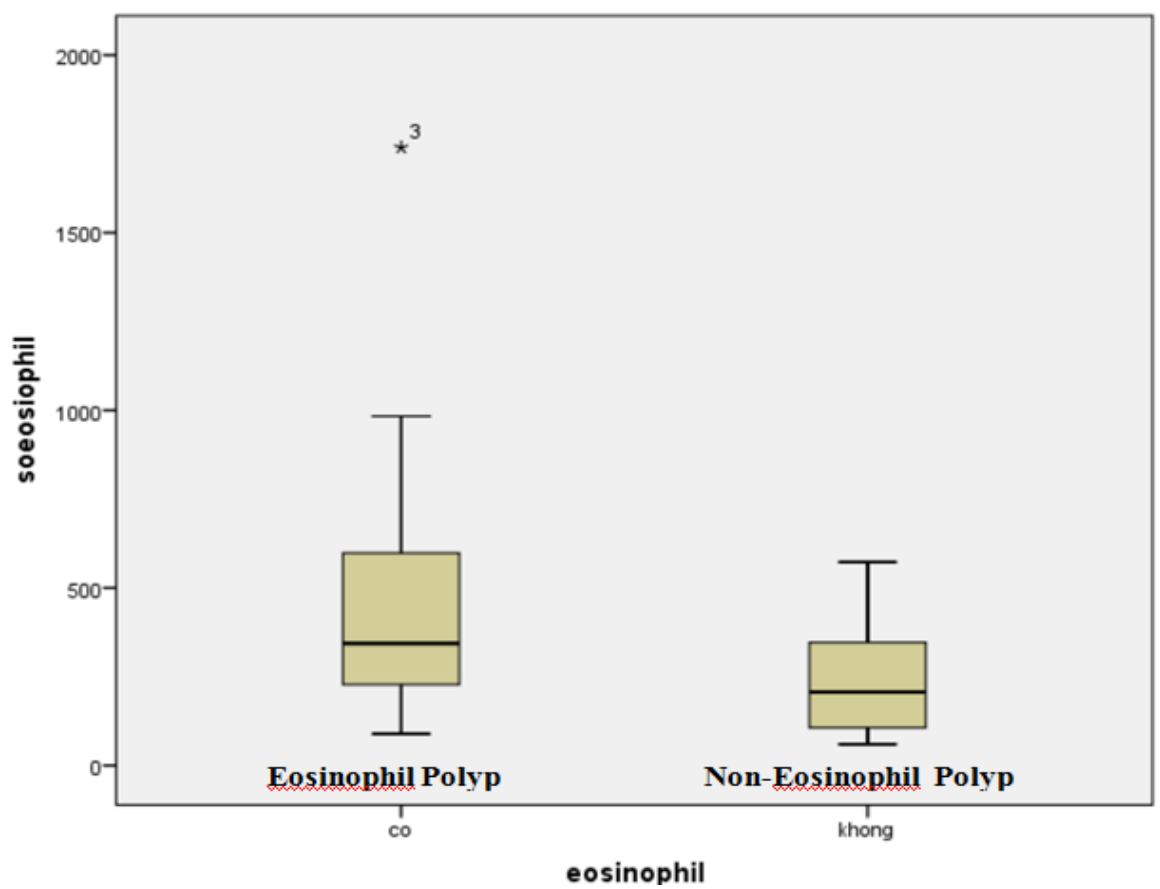

Figure 4. Quantity of Eosinophil in blood. Note: Quantity of blood Eosinophil of Eosinophil CRSwNP group: $452,1 \pm 346,05$ cells $/ \mu \mathrm{L}$; Non-Eosinophil. CRSwNP group : $249.8 \pm 158.5$ cells $/ \mu \mathrm{L}$. $(\mathrm{P}=0.004)$. 


\section{DISCUSSION}

Eosinophilic nasal polyps cause an increase in the objective and subjective severity of the disease, as well as an increased risk of relapse of the disease after sinus surgery (Ottaviano et al., 2015). It is important to note that the degree of tissue eosinophilia is extremely difficult to determine based on clinical symptoms; it cannot be predicted by SNOT-22 scores or the concomitant presence of asthma or other respiratory diseases (Steinke et al., 2017). At the same time, high plasma eosinophils indicate extensive mucosal damage (Gitomer et al., 2016).

Inflammation in eosinophilic polyps is mainly controlled by type 2 cytokines, namely IL-5 and IL-13, which can be produced from several immune cells, including Th2, mast cells and congenital lymphoid cells of group 2 (ILC2), especially induces eosinophilia cytokine IL-5 (Kato, 2015). Eosinophilic infiltration into the paranasal sinuses and nasal polyps can be mediated by the expression of PNAd (peripheral lymph nodeaddressin) in vascular endothelial cells, while severe eosinophilic CRS is often complicated by aspirin intolerance (Fujieda et al., 2019).

Asthma is a common concomitant disease in CRS and has pathophysiology similar to $C R S w N P$ (Orlandi et al., 2016). The presence of asthma is observed in $26-48 \%$ of patients with $C R S w N P$ (Alshoabi et al., 2020). About $85 \%$ of $C R S w N P s$ detect type 2 inflammatory patterns with an expression of IL-4, IL- 5, and IL-13, as well as a significant increase in IgE concentration, respectively, the degree of type 2 inflammation is associated with the severity of the disease, concomitant asthma, and relapse after operations (Bachert et al., 2017). It was found that during the pharmacological treatment of asthma in patients with concomitant $\mathrm{c}$, there was a side improvement in sinonasal symptoms (Smith et al., 2018). In our study, a high percentage of comorbid bronchial asthma was also observed in $C R S w N P$, which is consistent with the literature.

Allergic rhinitis is the most common concomitant pathology of CRSwNP (Heath J. et al., 2018). About $51-86 \%$ of patients with $C R S w N P$ are sensitized to at least one aeroallergen (Batra et al., 2013). The results of a number of studies indicate that the number of eosinophils in nasal polyps is significantly higher in patients with allergies compared to the non-allergic group, in addition, there is a higher expression of IL-4, IL-5, and IL-6 cytokines, as well as Th2 in allergic rhinitis (Koennecke et al., 2018). We found a statistically significantly higher percentage of concomitant allergic rhinitis with $C R S w N P$ in the Vietnamese population.

It is noted in the literature that most often nasal polyps are present in the form of bilateral inflammatory lesions that occur in the paranasal sinuses and protruding into the nasal airways under the middle nasal concha (Stevens et al., 2016). Our data indicate that bilateral localization of the lesion with eosinophil $C R S w N P$ in the Vietnamese population is highly likely.

Studies among Vietnamese people indicate that patients with CRS who did not have surgery have a significantly lower quality of life than healthy people (My Nguyen et al., 2019). At the same time, surgical intervention does not guarantee recovery. Relapse of the polyp after endoscopic sinus surgery is quite common, in particular, found in about $60-70 \%$ of patients (DeConde et al., 2017). In this regard, studies such as ours are focused on improving the therapy and subsequent quality of life of patients with $C R S w N P$. 


\section{CONCLUSIONS}

We conclude that $C R S w N P$ is a complex heterogeneous inflammatory disease. Eosinophilia plays an important role in the pathogenesis of this disease and significantly worsens the clinical symptoms. There are significant differences in the duration of the pathological manifestations, the presence of allergic rhinitis, bronchial asthma, and the severity of polyps in patients with eosinophilic versus non-eosinophilic $C R S w N P$.

The field of study of $C R S w N P$ needs reliable epidemiological data that are necessary for the optimal treatment of patients with bronchial asthma. Given the high prevalence of the disease, there is a need to continue research in the field of CRS in order to develop new therapeutic strategies to increase the effectiveness of treatment of patients suffering from this disease.

\section{ACKNOWLEDGMENTS}

The authors are thankful to National ENT Hospital for providing the means to complete the research.

\section{CONFLICTS OF INTEREST}

The authors declare no conflict of interest.

\section{REFERENCES}

Alshoabi SA, Binnuhaid AA, Gameraddin MB and Alsultan KD (2020). Histopathological analysis of sinonasal lesions associated with chronic rhinosinusitis and comparison with computed tomography diagnoses. Pak. J. Med. Sci. 36(2): 146-150.

Bachert C and Akdis CA (2016). Phenotypes and Emerging Endotypes of Chronic Rhinosinusitis. J. Allergy Clin. Immun. Pract. 4(4): 621-8.

Bachert C, Gevaert P and Hellings P (2017). Biotherapeutics in Chronic Rhinosinusitis with and without Nasal Polyps. $J$. Allergy Clin Immun. Pract. 5(6): 1512-1516.

Batra PS, Tong L and Citardi MJ (2013). Analysis of comorbidities and objective parameters in refractory chronic rhinosinusitis. Laryngoscope. 123 (7): 1-11.

DeConde A.S., Mace J.C., Levy J.M., Rudmik L., et al. (2017). Prevalence of polyp recurrence after endoscopic sinus surgery for chronic rhinosinusitis with nasal polyposis. Laryngoscope, 127(3):550-555.

Fokkens WJ, Lund V, Bachert C, Mullol J, et al. (2019). EUFOREA consensus on biologics for CRSwNP with or without asthma. Allergy. 74(12): 2312-2319.

Fujieda S, Imoto Y, Kato Y, Ninomiya T, et al. (2019). Eosinophilic chronic rhinosinusitis. Allergol. Int. 68(4): 403-412.

Gitomer SA, Fountain CR, Kingdom TT, Getz AE, et al. (2016). Clinical Examination of Tissue Eosinophilia in Patients with Chronic Rhinosinusitis and Nasal Polyposis. Otolaryngol. Head Neck Surg. 155(1): 173-8.

Heath J, Hartzell L, Putt C and Kennedy JL (2018). Chronic Rhinosinusitis in Children: Pathophysiology, Evaluation, and Medical Management. Curr. Allergy Asthma Rep. 18(7): 37.

Hopkins C (2019). Chronic Rhinosinusitis with Nasal Polyps. N. Eng. J. Med. 381(1): 55-63.

Kato A (2015). Immunopathology of chronic rhinosinusitis. Allergol. J. Int. 64(2): 121-30.

Koennecke M, Klimek L, Mullol J, Gevaert P, et al. (2018). Subtyping of polyposis nasi: phenotypes, endotypes and comorbidities. Allergol. J. Int. 27(2): 56-65.

Lou H, Zhang N, Bachert C and Zhang L (2018). Highlights of eosinophilic chronic rhinosinusitis with nasal polyps in definition, prognosis, and advancement. Int. Forum Allergy Rhinol. 8(11): 1218-1225.

My Nguyen DT, Vo TQ, Nguyen TD, Vu TQ, et al. (2019). Non- surgical chronic rhinosinusitis and quality of life: A Vietnamese perspective. J. Pak. Med. Assoc. 69 (Suppl. 2) (6): 20-27.

Orlandi RR, Kingdom TT, Hwang PH, Smith TL, et al. (2016). International Consensus Statement on Allergy and Rhinology: Rhinosinusitis. Int. Forum Allergy Rhinol. 1: 202-209. 
Ostovar A, Fokkens WJ, Vahdat K, Raeisi A, et al. (2019). Epidemiology of chronic rhinosinusitis in Bushehr, southwestern region of Iran: a GA2LEN study. Rhinology. 57(1): 43-48.

Ottaviano G, Cappellesso R, Mylonakis I, Lionello M, et al. (2015). Endoglin (CD105) expression in sinonasal polyposis. Eur. Arch. Otorhinolaryng. 272(11): 3367-3373.

Philpott CM, Erskine S, Hopkins C, Kumar N, et al. (2018). Prevalence of asthma, aspirin sensitivity and allergy in chronic rhinosinusitis: data from the UK National Chronic Rhinosinusitis Epidemiology Study. Respir. Res. 19(1): 129.

Shi JB, Fu QL, Zhang H, Cheng L, et al. (2015). Epidemiology of chronic rhinosinusitis: results from a cross-sectional survey in seven Chinese cities. Allergy. 70: 533-539.

Smith KA, Pulsipher A, Gabrielsen DA and Alt JA (2018). Biologics in Chronic Rhinosinusitis: An Update and Thoughts for Future Directions. Am. J. Rhinol. Allergy. 32(5): 412-423.

Steinke JW, Smith AR, Carpenter DJ, Patrie JT, et al. (2017). Lack of Efficacy of Symptoms and Medical History in Distinguishing the Degree of Eosinophilia in Nasal Polyps. J. Allergy Clin. Immunol. Pract. 5(6): 1582-1588.

Stevens WW, Schleimer RP and Kern RC (2016). Chronic Rhinosinusitis with Nasal Polyps. J. Allergy Clin. Immunol. Pract. 4(4): 565-572.

Tomassen P, Vandeplas G, Van Zele T, Cardell LO, et al. (2016). Inflammatory endotypes of chronic rhinosinusitis based on cluster analysis of biomarkers. J. Allergy Clin. Immunol. Pract. 137: 1449-1456.

Watelet JB, Dogne JM and Mullier F (2015). Remodeling and Repair inRhinosinusitis. Curr. Allergy Asthma Rep. 15(6): 34.

Workman AD, Kohanski MA, and Cohen NA (2018). Biomarkers in Chronic Rhinosinusitis with Nasal Polyps. Immunol. Allergy Clin. North Am. 38(4): 679-692. 